\title{
Perfil do Psicólogo Residente e Atuante em João Monlevade (MG): Perfil do Psicólogo Monlevadense
}

\author{
Aline Benício Muniz ${ }^{1}$ \\ Lorraynne Moura de Amorim ${ }^{1}$

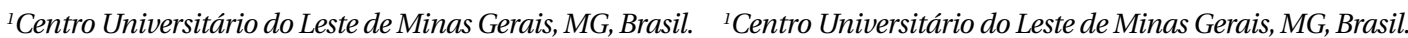 \\ Shyrlleen Christieny Assunção Alves ${ }^{1}$ \\ ${ }^{1}$ Centro Universitário do Leste de Minas Gerais, MG, Brasil.
}

Resumo: Este estudo realizou um levantamento do perfil do psicólogo residente e atuante no município de João Monlevade (MG). Trata-se de uma pesquisa descritivo-quantitativa, na qual a obtenção de dados foi realizada por meio de um questionário autopreenchido online. Participaram da pesquisa 35 psicólogos inscritos e ativos no Conselho Regional de Psicologia de Minas Gerais, residentes em João Monlevade, independentemente do sexo e da faixa etária. Após a coleta, os dados foram organizados, tabulados e analisados por meio de uma análise estatística. Os resultados demonstram que a maioria dos profissionais são mulheres, adultos jovens e graduados na rede de ensino privada. Tais profissionais tendem a atuar nas áreas clínica e organizacional, utilizando a abordagem psicanalítica. Grande parte atua exclusivamente em psicologia, exerce trabalho autônomo e de consultoria. Embora haja limitações, o estudo apresenta maior porcentagem de psicólogos que recebem salários inferiores quando comparado com outras pesquisas e corrobora com as mesmas em outras questões.

Palavras-chave: Atuação do Psicólogo, Formação em Psicologia, Inserção Profissional, Mercado de Trabalho.

\section{Profile of the Resident and Acting Psychologist in João Monlevade, Minas Gerais}

Abstract: This study aimed to carry out a survey of the profile of the resident and active psychologist in the region of João Monlevade, Minas Gerais, Brazil. This is a descriptive quantitative research, the data collection was performed through a self-completed online questionnaire with 35 psychologists enrolled and active in the Regional Psychology Council of Minas Gerais, residents of João Monlevade, regardless of gender and age group. The data collected was organized, tabulated and analyzed by a statistical analysis. The results indicates that most of the professionals are women, young adults, graduates of the private education system, tend to work in the clinical and organizational areas and use the psychoanalytic approach. Most of them work exclusively in psychology, autonomously and as consultants. Although there are limitations in the research, the study presents a higher percentage of psychologists who receive lower salaries when compared to other researches and corroborates with them in other subjects.

Keywords: Activity of a Psychologist, Study of Psychology, Professional Insertion, Job Market.

\section{Perfil del Psicólogo Residente y Actuante en João Monlevade, Minas Gerais}

Resumen: Este estudio objetivó realizar un levantamiento del perfil del psicólogo residente y actuante en el municipio de João Monlevade, Minas Gerais, Brasil. Se trata de una investigación cuntativa descriptiva, la obtención de datos se realizó a través de un cuestionario auto rellenado en línea. Participaron 35 psicólogos inscritos y activos en el Consejo Regional de Psicología de 
Minas Gerais, residentes en João Monlevade, independientemente del sexo y del grupo de edad. Después de la recolección, los datos fueron organizados, tabulados y analizados por medio de un análisis estadístico. Los resultados demuestran que la mayoría de los profesionales son mujeres, adultos jóvenes y graduados en la red privada. Tenden actuar en las áreas clínica y organizacional y utilizar el abordaje psicoanalítico. Gran parte actúa exclusivamente en psicología, ejerce trabajo autónomo y de consultoría. Aunque hay limitaciones, el estudio presenta un mayor porcentaje de psicólogos que reciben salarios inferiores cuando se compara con otras investigaciones y corrobora con las mismas en otras cuestiones.

Palabras clave: Actuación del Psicólogo, Formación en Psicología, Inserción Profesional, Mercado de Trabajo.

\section{Introdução}

A psicologia, enquanto formação, atuação e prática, contribui para a construção de conhecimento sobre pessoas, o que proporciona progresso científico e desenvolvimento do corpo social. Por meio de suas teorias, conceitos e explicações sobre fenômenos humanos, ela favorece a conscientização acerca da vida individual e grupal. Os psicólogos trabalham em prol de ações afirmativas, denunciam injustiças e lutam pela qualidade de vida e bem-estar da população. Além disso, buscam conscientizar a população quanto ao papel deles na construção de um futuro melhor (Malvezzi, 2010).

A criação da profissão constitui importante fator na evolução da psicologia no país, presente em toda sociedade e reconhecida pelo potencial de seus serviços nos múltiplos campos de atuação. A regulamentação da psicologia ocorreu em 27 de agosto de 1962, por meio da Lei no 4.119 (Brasil, 1962) e, desde então, a área cresceu, tanto no âmbito acadêmico e de atuação quanto no número de profissionais. O Brasil conta com 313.681 psicólogos cadastrados no Conselho Federal de Psicologia, dos quais 34.549 estão registrados no Conselho Regional de Psicologia de Minas Gerais (Conselho Federal de Psicologia, 2018).

O aumento de cursos de graduação e de profissionais possibilita maior acessibilidade à população aos serviços psicológicos. Nesse sentido, a psicologia torna-se um campo necessário e indispensável para a sociedade, embora em constante construção e reconstrução (Malvezzi, 2010). Esse crescimento demonstra uma abertura positiva por parte dos indivíduos e das instituições, dispostos a receberem uma contribuição especializada para auxiliar em suas questões. O exercício da psicologia é diversificado, e o profissional se insere de várias formas no mercado de trabalho dos municípios ao buscar atender à sociedade e a suas demandas.

João Monlevade é um município do interior de Minas Gerais, situado ao leste da capital, Belo Horizonte, e sua população estimada é de 79.590 habitantes (Instituto Brasileiro de Geografia e Estatística, 2017). A cidade foi emancipada no século XIX, possui como fator de crescimento populacional e econômico a instalação da ArcelorMittal Aços Longos, antes chamada Belgo Mineira. O setor industrial apresenta extrema importância para o desenvolvimento local - representava 50\% do valor adicionado à cidade em 2012. O setor terciário, representante dos outros $50 \%$, é responsável por seu título de cidade-polo regional, graças à diversificação de serviços (Serviço Brasileiro de Apoio às Micro e Pequenas Empresas, 2014). Acerca dos serviços de saúde no município, até o ano de 2009, havia 54 estabelecimentos, 17 públicos e 37 privados. Sobre as características empresariais, João Monlevade possuía 1.449 empreendedores individuais, 3.104 empresas de micro e pequeno portes e 27 empresas de médio e grande portes em 2012. Destes, $43 \%$ eram voltados para serviços, $41 \%$ para comércio, $15 \%$ para área industrial e apenas $1 \%$ para agropecuária (Serviço Brasileiro de Apoio às Micro e Pequenas Empresas, 2014; Instituto Brasileiro de Geografia e Estatística, 2017). A cidade contava com 43 instituições de ensino de nível básico até 2013, e 8 instituições de ensino de nível superior até 2012 (Serviço Brasileiro de Apoio às Micro e Pequenas Empresas, 2014). Vale ressaltar que não há oferta do curso de graduação em psicologia em nenhuma das instituições de ensino superior da cidade; em consequência, todos os profissionais que ali atuam se formaram em outros municípios. Diante dessa característica, propomos a seguinte questão: qual o perfil do psicólogo residente e atuante em João Monlevade (MG)? 
Dessa forma, o presente estudo objetivou realizar um levantamento do perfil do psicólogo residente e atuante no município de João Monlevade. Para isso, buscou-se caracterizar o psicólogo residente e atuante no município; investigar os aspectos formativos da psicologia; identificar as áreas de atuação de maior predominância; e descrever a inserção desse psicólogo no mercado de trabalho da cidade.

Ademais, o estudo visou comparar os resultados alcançados com os achados de Bastos e Gondim no livro O trabalho do psicólogo no Brasil (Bastos \& Gondim, 2010).A escolha da obra se deveà sua relevância no meio científico e acadêmico, sendo frequentemente referenciada por reunir dados capazes de representar a atuação profissional dos psicólogos na atualidade.

Este artigo não pretende fazer uma descrição exaustiva dos tópicos mencionados nos objetivos, sendo a intenção introduzir o leitor aos aspectos considerados importantes dentro da temática. Ao longo do artigo, ele observará uma breve caracterização do perfil do psicólogo brasileiro, baseado em pesquisas de grande significância na área. A seguir, passará por questões que viabilizaram o reconhecimento da psicologia no Brasil enquanto ciência e profissão. Informações sobre a atuação e a inserção do psicólogo no mercado de trabalho serão apresentadas com o objetivo de contextualizar a profissão no cenário brasileiro. Ao final, o leitor poderá visualizar a correlação dos aspectos supracitados com os dados da pesquisa.

A escolha do tema surgiu durante a participação no projeto de iniciação científica "A atuação do psicólogo organizacional". A pesquisa, cujo escopo perfaz a região do Vale do Aço, foi incentivada pela Fundação de Amparo à Pesquisa do Estado de Minas Gerais, com o apoio do Centro Universitário do Leste de Minas Gerais. Através dessa vivência, as autoras confirmaram o interesse por pesquisa acadêmica e por um tema que estivesse ligado à formação, à atuação e ao compromisso social do psicólogo. A proposta deste trabalho possibilitou-lhes conhecer outro território marcado por indústrias siderúrgicas e pertencente à subsede leste do Conselho Regional de Psicologia de Minas Gerais (CRP-04). Nesse contexto, o assunto atende aos objetivos acadêmicos e profissionais das pesquisadoras e possibilita a realização de futuras pesquisas que enriquecerão o desenvolvimento profissional.

O presente estudo poderá ser utilizado como base para futuros trabalhos e realização de investigações mais amplas sobre a atuação do psicólogo na cidade de João Monlevade, onde não há registros de pesquisas desse cunho realizadas anteriormente. Dessa maneira, pretende contribuir com os psicólogos atuantes no mercado de trabalho e acadêmicos em psicologia naturais de João Monlevade, assim como com cidadãos monlevadenses interessados em obter essa formação profissional.

\section{Quem é o psicólogo brasileiro?}

Em 1988, o Conselho Federal de Psicologia (CFP) publicou uma pesquisa sobre a profissão do psicólogo no Brasil. Pela primeira vez no cenário nacional, informações foram coletadas sobre atuação, abordagem, formação, identidade, papel social, remuneração, status etc. Em 2010, o Grupo de Trabalho de Psicologia Organizacional e do Trabalho (GT-PO\&T), da Associação Nacional de Pesquisa e Pós-Graduação em Psicologia (Anpepp), publicou pesquisa semelhante com o título "A ocupação do psicólogo: um exame à luz das categorias da psicologia organizacional e do trabalho", que atualizou os conhecimentos sobre o psicólogo brasileiro. Os dados coletados permitiram verificar as mudanças que ocorreram em um intervalo aproximado de vinte anos (Bastos, Gondim, \& BorgesAndrade, 2010; Rezende, 2014).

A pesquisa, publicada em 2010, apontou crescimento da psicologia no Brasil a partir do número de profissionais inscritos no CFP. A área é caracterizada por profissionais jovens, os psicólogos avaliados possuem 10,6 anos de formação e se encontram mais avançados profissionalmente; $31,1 \%$ deles vivem com cônjuge e filhos, $27,4 \%$ moram com a família de origem, $21,6 \%$ residem com cônjuge ou companheiro, 10,4\% vivem sozinhos, $7,2 \%$ moram com os filhos, e $2,4 \%$ residem com amigos (Bastos, Gondim, \& Rodrigues, 2010).

Um estudo nacional realizado pelo CFP com psicólogas brasileiras revelou que a região Nordeste possui a menor porcentagem de psicólogas que moram com parceiros do sexo oposto. As regiões Norte e Sudeste são as que concentram maior porcentagem de psicólogas que moram com os filhos. Na pesquisa realizada pelo CFP, $20 \%$ das psicólogas moram apenas com os filhos, mas não com o companheiro (Lhullier \& Roslindo, 2013).

A psicologia é caracterizada como uma profissão feminina, na qual o número de mulheres supera consideravelmente o de homens (Bastos et al., 2010; Conselho Regional de Psicologia do Paraná, 2010; Pacheco, 2013; Rezende, 2014). Cabe acrescentar um comentário em referência a isso: atualmente, alguns 
artigos no campo da psicologia utilizam o termo "psicóloga" por considerar o número expressivo de mulheres na profissão. Mas, ao longo deste artigo, as autoras optaram pelo termo "psicólogo". Primeiramente, o termo está em concordância com a norma culta brasileira, que estabelece o uso do pronome masculino em substantivos distintos quando utilizados no plural. Em segundo lugar, o uso de "psicóloga" avigoraria a crença de que a psicologia é uma profissão feminina, por culturalmente se apresentar como apropriada às mulheres. Reforçaria o estereótipo sexista que associa ao gênero feminino papéis que remetem a cuidado, percepção, fragilidade e paciência, enquanto ao masculino são atribuídas características como destemor, poder, força, agressividade e liderança. Por fim, entende-se que essa atitude manteria a dicotomização entre carreiras masculinas e femininas e ignoraria as subjetividades expressas por cada indivíduo de forma única e singular.

A escolha da profissão é permeada por vários fatores determinantes na tomada de decisão, tais como: culturais, econômicos, educacionais, familiares, políticos, psicológicos e sociais, o que torna a escolha profissional um processo multi e sobredeterminado (Nepomuceno \& Witter, 2010). As obras que abordam a construção da carreira no campo da psicologia utilizam os conceitos de fatores internos e externos. Apesar de haver, por vezes, discordância entre teóricos sobre esses termos, o presente artigo optou por utilizá-los para promover uma harmonização na análise de resultados e uma discussão que serão desenvolvidas posteriormente.

Os fatores internos e externos podem influenciar o direcionamento da carreira, sendo considerados fatores internos a identificação, interesse e habilidades compatíveis à área, enquanto os fatores externos são guiados por remuneração, status social e mercado de trabalho. Os psicólogos tendem a eleger a psicologia como profissão por razões internas. Geralmente, conferem sua escolha profissional tanto com vistas a ajudar o outro quanto para autoajuda. Inclusive, é comum alunos e psicólogos correlacionarem a atuação do profissional de psicologia à área assistencialista, voltada a "ajudar as pessoas". Na análise da escolha da profissão, os psicólogos atribuem pouca importância aos fatores externos (Bardagi, Bizarro, Andrade, Audibert, \& Lassance, 2008; Bastos et al., 2010; Gondim, Magalhães, \& Bastos, 2010).
Quanto à escolha pela área de atuação, pode haver a influência de terceiros e das experiências durante a formação. Nesse âmbito, o fator interno exerce a mesma influência quando comparada à escolha profissional. No entanto, fatores externos apresentam maior relevância quando se trata da escolha pela área de atuação. É observada a mesma proporção independente da área: clínica, docente, escolar, organizacional e de saúde. Em suma, os resultados da pesquisa de 2010 evidenciam que tanto a escolha da profissão quanto a escolha da área de atuação são guiadas por razões internas (Bastos et al., 2010; Gondim et al., 2010).

Quanto à distribuição de psicólogos no Brasil, de acordo com Bastos et al. (2010), a região de maior aglomeração é a Sudeste, tendo o estado de São Paulo com o maior número de profissionais, embora esse número tenha diminuído quando comparado ao da pesquisa de 1988. Em contrapartida, houve uma expansão no número de psicólogos nas regiões Centro-Oeste, Norte, Nordeste e Sul. A investigação realizada pelo GT-PO\&T da Anpepp revelou uma interiorização da profissão ao longo dos anos, que antes era predominante nas capitais do país. Essa mudança não altera o fato de que os psicólogos continuam a atender cidades de médio e grande portes (Bastos et al., 2010).

A expansão da área psicológica no Brasil está diretamente associada à ampliação de cursos de psicologia e do número de psicólogos inscritos nos Conselhos Regionais. Mais da metade dos concluintes se credencia para ser psicólogo, mas nem todos os formandos se inserem na profissão. A estimativa é que cerca de um terço de graduados não se habilita para atuar na área. Nessa perspectiva, muitos estados apresentam menor quantidade de psicólogos formados do que em atividade profissional, o que sugere um processo de importação de profissionais para esses locais (Bastos et al., 2010).

Em relação à formação básica, a pesquisa de 2010 observou que, embora o número de egressos no ensino privado seja superior ao da rede de ensino pública, são os formandos nas instituições estaduais e federais que apresentam melhor performance no Exame Nacional de Desempenho dos Estudantes (Enade) realizado pelo Instituto Nacional de Estudos e Pesquisas Educacionais Anísio Teixeira (Inep) (Bastos et al., 2010; Conselho Regional de Psicologia do Paraná, 2010; Rezende, 2014; Santos, Monteiro, Torres, Sousa, \& Coelho, 2014; Yamamoto, Souza, Silva, \& Zanelli, 2010).

Quanto à formação continuada, as pós-graduações latu e stricto sensu fazem parte da realidade dos 
psicólogos brasileiros. Geralmente, o mestrado e/ou o doutorado atraem psicólogos que se interessam pela carreira acadêmica. No geral, $60,3 \%$ da amostra investigada participa ou participou de alguma modalidade de pós-graduação (Bastos et al., 2010; Conselho Regional de Psicologia do Paraná, 2010; Santos et al., 2014; Yamamoto et al., 2010). Tendo em vista o objetivo proposto por este estudo, é importante contextualizar o cenário de formação, inserção e atuação do psicólogo no Brasil.

\section{A formação do psicólogo}

O surgimento da psicologia no Brasil está diretamente associado aos acontecimentos históricos do país. Ideias vinculadas à psicologia datam desde a época colonial, quando a área estava em estado embrionário na nação. Nesse período, a psicologia se alastrava nos textos que abordavam assuntos relacionados a medicina, educação, política e teologia. Foi só depois da criação de instituições de ensino superior é que se iniciou a produção propriamente dita de um saber psicológico no Brasil (Pessotti, 1988; Rezende, 2014).

A inserção da psicologia ocorreu lentamente nos currículos de determinados cursos superiores, integrando as grades curriculares de direito, filosofia, medicina, pedagogia e teologia. Inicialmente, ela se apresentava como disciplina independente e optativa, passando depois a obrigatória (Mancebo, 1997; Pessotti, 1988). Segundo Lisboa e Barbosa (2009), as disciplinas de psicologia eram vistas como complementação na formação de vários profissionais, ainda não sendo reconhecidas como compondo uma área específica, com relevância própria.

Por meio do Decreto-Lei no 9.092, foi institucionalizada a formação do psicólogo brasileiro. Esse decreto estabelecia que os profissionais interessados em exercer a psicologia deveriam frequentar por três anos um curso de antropologia, biologia, estatística, filosofia ou fisiologia e, posteriormente, participar de um curso especializado em psicologia. Apesar desse grande avanço, a formação do especialista era precária e superficial. A partir da regulamentação da profissão em 1962 como ciência autônoma no Brasil, foram despertadas mudanças na formação acadêmica e na atuação do psicólogo brasileiro (Lisboa \& Barbosa, 2009).

Nesse sentido, o Parecer no $403 / 62$ foi emitido pelo Conselho Federal de Educação com o objetivo de firmar o currículo mínimo e a duração dos cursos de psicologia (Brasil, 1962; Mancebo, 1997; Rezende, 2014). Esse documento definiu duração de quatro anos para a obtenção de título de bacharelado e licenciatura, e de cinco anos para a formação de psicólogo (Brasil, 1962; Rezende, 2014). O currículo mínimo tinha ênfase em disciplinas profissionalizantes, o que significava uma formação profissional tecnicista e intervencionista, na qual o uso de instrumentos psicológicos eram utilizados de modo padronizado e desvinculado da realidade social (Amendola, 2014).

Ao longo dos anos, o currículo mínimo foi alvo de diversas críticas, o que propiciou o surgimento dos projetos de Diretrizes Curriculares Nacionais (DCN) propostos para os cursos de graduação em psicologia (Amendola, 2014; Bardagi et al., 2008; Lisboa \& Barbosa, 2009; Rezende, 2014). Atualmente, vigora a Resolução no 005/11 emitida pelo Conselho Federal de Educação/Câmara de Educação Superior, cujo propósito é orientar a formação e a atuação profissional do psicólogo, e ainda a licenciatura em psicologia (Amendola, 2014; Brasil, 2011).

As DCN orientam medidas para que esse profissional obtenha uma formação básica e generalista. Com essa formação, entende-se que os psicólogos podem atuar em diferentes áreas, atender em diversas regiões do Brasil e acolher as demandas do público brasileiro. Todavia, apesar do desenvolvimento de novos projetos de DCN, a formação do psicólogo continua sendo alvo de questionamentos constantes (Amendola, 2014). Para Lisboa e Barbosa (2009), as críticas são importantes e revelam uma insatisfação com a formação básica, pós-graduada e complementar, com os currículos, estágios e áreas de atuação.

As críticas se estendem à atuação do psicólogo que frequentemente é desvinculada da realidade brasileira e voltada para a área clínica. As necessidades da sociedade atual não são estáticas, portanto, a atuação do psicólogo é influenciada por essas mudanças. Os profissionais devem se adaptar às transformações e buscar uma formação que lhes permita atender às áreas emergentes da psicologia $\mathrm{e}$ estar mais próximos das pessoas (Bardagi et al., 2008; Mancebo, 1997; Rezende, 2014).

A formação acadêmica e profissional fundamenta a atuação dos profissionais. As instituições de ensino superior são responsáveis pela formação de seus estudantes. Igualmente, os alunos de psicologia devem investir em seu próprio desenvolvimento profissional para acompanhar as demandas do mercado de trabalho e dos clientes (Amendola, 2014). Sugere-se que a formação acadêmica e os esforços dos alunos 
caminhem lado a lado, de modo que uma postura crítica e reflexiva seja adotada quanto à atuação profissional do psicólogo (Amendola, 2014; Rezende, 2014).

\section{O psicólogo no mercado de trabalho}

Após completar a graduação e conferir o diploma, o psicólogo volta-se à inserção no mercado de trabalho. Esse momento entre a conclusão do curso e a atuação profissional é vivenciado por cada pessoa de acordo com fatores variáveis, atrelados a ela própria e a seu contexto. A ocupação profissional representa um aspecto importante na construção da identidade do indivíduo dentro e fora de seu local de trabalho, como uma ponte que o insere profissionalmente na sociedade. O psicólogo que possui identificação com o seu trabalho faz refletir em sua atuação o comprometimento com a profissão (Pacheco, 2013; Rezende, 2014).

De acordo com Malvezzi, Souza e Zanelli (2010), dois terços dos graduados em psicologia atuam em sua área de formação, o que demonstra uma profissão organizada em relação ao mercado de trabalho. A expansão da psicologia propicia ao profissional assumir novos paradigmas sociais e estar presente nos setores da saúde e do trabalho, bem como nas áreas esportiva, jurídica etc. Ser psicólogo é uma profissão plural, com várias especialidades, diferentes instituições e distintas opções de vínculo (Malvezzi et al., 2010).

Ao analisarmos aspectos do primeiro emprego, a atuação em clínica e saúde aparece como predominante, seguida da organizacional e do trabalho. Entre as atividades realizadas por esses profissionais, a aplicação de testes é a principal em todos os contextos, exceto nas ONGs. Outras atividades citadas são o diagnóstico, a assistência psicológica, a realização de tarefas administrativas e a docência. Os psicólogos atuam tanto individualmente quanto em equipes multidisciplinares. Acerca da escolha de abordagens, a psicanálise é frequentemente destacada, seguida da atuação pluralista em duas ou três abordagens diferentes. A maioria dos psicólogos apresenta jornada de trabalho dupla ou tripla, desempenhando atividades profissionais em mais de uma área de atuação (Heloani, Macêdo, \& Cassiolato, 2010; Malvezzi et al., 2010; Pacheco, 2013).

Sobre a remuneração da profissão, é possível que haja disparidades de salários entre as áreas dentro da psicologia, entre os serviços público e privado, entre períodos de trabalho em tempo integral e parcial. O setor público concentra $40,3 \%$ dos psicólogos, e as empresas privadas e organizações sem fins lucrativos empregam $60 \%$. A maioria dos profissionais do setor privado presta serviços autônomos como consultoria, mas existem os contratados pela Consolidação das Leis do Trabalho (CLT). Há um número maior de psicólogos contratados como docentes no setor privado $(27,5 \%)$ em relação aos que atuam no setor público $(14,5 \%)$. Esses aspectos estão ligados ao fato de os cursos de graduação em psicologia estarem concentrados em instituições privadas (Macêdo, Heloani, \& Cassiolato, 2010).

As áreas de atuação mais frequentes entre os psicólogos são a clínica, organizacional, saúde, docência, escolar e social. A área jurídica aparece em menor porcentagem do que as outras. Os profissionais exercem desde atuação exclusiva até combinada entre duas áreas ou mais. A área na qual há maior atuação exclusiva é a organizacional, seguida de clínica e saúde; entre duas combinações, clínica/saúde é a que mais aparece; e, entre três combinações, clínica/organizacional/saúde (Gondim, Bastos, \& Peixoto, 2010).

Ao investigarem a imagem da profissão, PuentePalacios, Abbad e Martins (2010) observaram percepções favoráveis no que se refere à abrangência social, à credibilidade, ao prestígio, ao reconhecimento, ao respeito e ao status do psicólogo em equipes inter $\mathrm{e}$ multiprofissionais. No entanto, os participantes avaliaram a profissão como mal remunerada.

\section{Metodologia}

Trata-se de uma pesquisa quantitativa quanto à forma de sua abordagem e descritiva em relação a seus objetivos (Silveira \& Córdova, 2009). Segundo Gil (2008), as pesquisas de levantamento possuem uma grande população a ponto de ser impossível considerá-la em sua totalidade. Diante disso, trabalhou-se com uma amostra composta por 35 psicólogos, inscritos e ativos no Conselho Regional de Psicologia de Minas Gerais, residentes na cidade de João Monlevade, independentemente do sexo e da faixa etária. Foi utilizada a amostragem não probabilística por julgamento (Gil, 2008), na qual as pesquisadoras buscaram as informações de contato dos psicólogos por meio de grupos de psicólogos do município, indicação de pessoas conhecidas e pesquisas em meios eletrônicos.

A obtenção de dados foi realizada por meio de questionário autopreenchido on-line, criado através da plataforma Google Drive no aplicativo Google Forms. A escolha por esse instrumento em específico permitiu maior alcance de pessoas em curto período 
de tempo e proporcionou os participantes a opção de responder ao questionário no momento em que preferissem. Assim, o único material necessário seria um dispositivo eletrônico com acesso à internet, gerando menos custo para as pesquisadoras.

O questionário continha 23 perguntas, 12 de múltipla escolha, 9 com caixas de seleção e 2 abertas. Elas referiam à idade, ao sexo, à moradia, à formação, às áreas de atuação, às abordagens teórico-metodológicas, à natureza das atividades, à jornada de trabalho, ao salário e à percepção sobre o mercado de trabalho na cidade. Durante a elaboração do questionário, não foram abordados os seguintes tópicos: estado civil, tempo de formação, classe social, pertencimento étnico-racial, áreas de especialização e processo de escolha da área de atuação. As autoras optaram por não incluir esses aspectos por acreditar que um questionário demasiadamente longo poderia ser cansativo para o respondente e gerar maior evasão durante sua aplicação. As questões postas não eram obrigatórias; em função disso, algumas obtiveram não respostas, tais como as que referiam às abordagens e à percepção do psicólogo sobre o mercado. Foram usadas como referência as questões utilizadas nos instrumentos apontados no livro O trabalho do psicólogo no Brasil (Bastos \& Gondim, 2010), com o intuito de responder ao problema da pesquisa. Foi realizado um pré-teste para identificar problemas que poderiam interferir na coleta e no armazenamento dos dados.

As pesquisadoras fizeram contato com 55 pessoas, 2 clínicas de psicologia e 1 setor de recursos humanos de uma empresa da região por meio de e-mail, ligação e/ou mensagem para uma breve apresentação da pesquisa e o convite para participação. Foram disponibilizados dados sobre o tema, os objetivos e a metodologia para fins de esclarecimento, e o link para acesso ao Termo de Consentimento Livre e Esclarecido e ao questionário. No total, 35 psicólogos participaram da pesquisa. Após a leitura do questionário e seu preenchimento, as respostas foram enviadas diretamente para o banco de dados online das pesquisadoras, no qual foram organizadas, tabuladas e interpretadas por meio de análise estatística. Em seguida, os dados foram analisados por meio de gráficos e/ou tabelas gerados pelo próprio aplicativo Google Forms, de modo a permitir a interpretação dos resultados (Gerhardt, Ramos, Riquinho, \& Santos, 2009).
Ressalte-se que o projeto da presente pesquisa foi aprovado pelo Comitê de Ética em Pesquisa em Seres Humanos do Centro Universitário do Leste de Minas Gerais, sob o registro de Protocolo no 2.451.660, seguindo as normas da Resolução $\mathrm{n}^{\circ} 466$, de 12 de dezembro de 2012, do Conselho Nacional de Saúde (Brasil, 2012).

\section{Resultados e discussões}

Os dados desta pesquisa apresentam similaridade com outros levantamentos sobre o perfil do psicólogo de cunho nacional e regional. A amostra principal da pesquisa foi composta por 35 psicólogos do município de João Monlevade, Minas Gerais. Em algumas categorias, o número de participantes é inferior ao da amostra principal, em vista da não obrigatoriedade de resposta a qualquer questão que o participante não se sentisse à vontade em oferecer.

As autoras elegeram cinco pesquisas em território brasileiro com objetivos similares, sendo elas: "A ocupação do psicólogo: um exame à luz das categorias da psicologia organizacional e do trabalho" (Bastos \& Gondim, 2010); "Levantamento do perfil profissional e das condições de trabalho dos psicólogos do Paraná - CRP-08" (Conselho Regional de Psicologia do Paraná, 2010); "Perfil do psicólogo na região do Vale do Aço - MG"; "Perfil dos psicólogos inscritos na subsede leste do CRP-04" (Souza \& Correia, 2007); e "Pesquisa de opinião com psicólogos inscritos no Conselho Federal de Psicologia" (Conselho Federal de Psicologia, 2004). As cinco pesquisas foram consideradas representativas das informações reveladas nesta investigação e suficientes para fazer a análise dos dados.

Os resultados foram agrupados em quatro tópicos apresentados a seguir: caracterização dos psicólogos, formação acadêmica e profissional, áreas de atuação e inserção profissional.

\section{Caracterização dos psicólogos}

Tabela 1

Caracterização dos psicólogos.

\begin{tabular}{ccc}
\hline Sexo & Frequência & $\mathbf{\%}$ \\
\hline Feminino & 30 & 85,7 \\
Masculino & 5 & 14,3 \\
\hline Total & 35 & 100 \\
\hline & & continua...
\end{tabular}




\begin{tabular}{ccc}
...continuação & & \\
\hline Idade & Frequência & \% \\
\hline$\leq 24$ & 1 & 2,9 \\
25 a 29 & 17 & 48,6 \\
30 a 34 & 6 & 17,1 \\
35 a 39 & 3 & 8,6 \\
40 a 44 & 4 & 11,4 \\
45 a 49 & 4 & 11,4 \\
\hline Total & 35 & 100 \\
\hline
\end{tabular}

Fonte: dados apurados pelas pesquisadoras.

Conforme a Tabela 1, a maioria dos psicólogos inscritos no CRP e atuantes em João Monlevade é do sexo feminino $(85,7 \%)$, com baixa presença de representantes do sexo masculino (14,3\%). Esse dado corrobora a pesquisa de âmbito nacional publicada no livro O trabalho do psicólogo no Brasil, cuja proporção do gênero feminino na profissão chega a $86,6 \%$ (Bastos et al., 2010). Em uma pesquisa sobre o perfil do psicólogo paranaense, da amostra total $(n=2.167), 88,6 \%$ eram mulheres (Conselho Regional de Psicologia do Paraná, 2010). Outro estudo inscrito na subsede leste do CRP-MG, sobre o perfil de psicólogos atuantes em Governador Valadares (MG), constatou que, de 85 participantes, $88,2 \%$ pertenciam ao sexo feminino (Santos et al., 2014). Essa realidade foi evidenciada igualmente na pesquisa de opinião pública realizada com 2 mil psicólogos inscritos no CFP em 2004, e na pesquisa realizada em 2007 com 54 psicólogos que atuam na região do Vale do Aço (Conselho Federal de Psicologia, 2004; Souza \& Correia, 2007).

A forte presença feminina na profissão pode sugerir desigualdades no mercado de trabalho, regime de trabalho e valor social. Profissões vinculadas ao gênero feminino tendem a ser menos valorizadas perante a sociedade quando comparadas a atividades laborais associadas aos homens, interferindo diretamente no número de mulheres ocupando altos cargos e remunerações - o que, mais uma vez, confirma os dados da pesquisa de Bastos et al. (2010). Apesar disso, os dados evidenciam a alta presença feminina em cursos de ensino superior brasileiro, o que pode ser considerado uma conquista para as mulheres nos últimos anos. Em João Monlevade, $6 \%$ das mulheres do município possuíam ensino superior, contra $4 \%$ dos homens (Serviço Brasileiro deApoio às Micro e Pequenas Empresas, 2014).

Nesta pesquisa, a idade média encontrada foi de 32,25 anos. Prevaleceram os participantes entre 25 e
29 anos de idade, seguidos por profissionais com idades entre 30 e 34 anos, compondo $65,7 \%$ da amostra (Ver Tabela 1). Vale lembrar que a psicologia está regulamentada no país há 55 anos, em conformidade à emancipação da cidade de João Monlevade, ocorrida há 56 anos. Além disso, segundo o material publicado pelo Sebrae (2014) sobre a identidade dos municípios mineiros, entre a população residente na cidade, a faixa etária prevalente de homens e mulheres é de 20 a 30 anos. Essas informações explicariam o perfil jovem dos psicólogos monlevadenses.

Bastos et al. (2010) indicaram, numa pesquisa de abrangência nacional, que a idade média do psicólogo brasileiro é de 36,7 anos - 50\% da amostragem analisada tinha até 34 anos. Sintomaticamente, a idade de $68,6 \%$ dos psicólogos de João Monlevade é de até 34 anos. No estudo realizado pelo Conselho Regional de Psicologia do Paraná (2010), predominaram participantes da faixa etária de 25 a 29 anos, corroborando o resultado da presente pesquisa. Santos et al. (2014) identificaram altos índices de psicólogos com idades entre 26 e 30 anos, compondo 30,6\% da amostra. Na região metropolitana do Vale do Aço, havia maior número de psicólogos entre 26 e 45 anos de idade (Souza \& Correia, 2007). Esses dados indicam um alto número de adultos jovens na profissão. Importante ressaltar que, especificamente nesta pesquisa, houve maior interesse de participação por parte dos adultos jovens. Essa característica poderia sugerir que, em meio a tantas inovações tecnológicas e novas profissões, ainda há jovens e adultos jovens que possuem uma afeição por áreas ditas assistencialistas.

Quanto ao status de moradia, no Gráfico 1, 60\% dos psicólogos moram com a família de origem (pais, avós, parentes etc.) e nenhum reside com amigos. $\mathrm{Na}$ pesquisa nacional predominaram os profissionais que residem com o cônjuge e os filhos, $31,1 \%$. Há uma diferença considerável entre os participantes que residem com cônjuge e/ou filhos na pesquisa nacional $(59,9 \%)$ e na investigação no município de João Monlevade (31,4\%) (Bastos et al., 2010). Quando são analisadas a condição de moradia e a idade, observa-se que o número de psicólogos que reside com a família de origem é alto e está diretamente relacionado ao atributo jovem dos participantes. Infere-se que esses resultados se relacionam ao fato de que, atualmente, os adultos jovens estão deixando a casa dos pais tardiamente. É possível que fatores econômicos, emocionais e sociais estejam atrelados a esse fenômeno. 


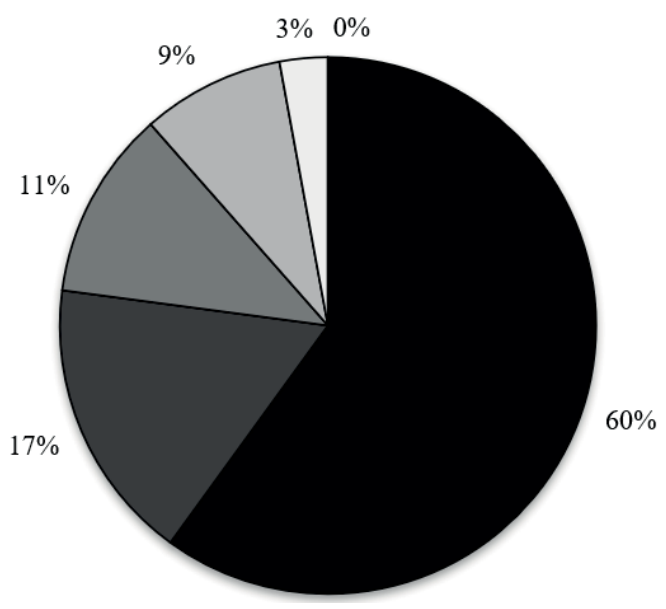

\author{
Mora com a família de \\ origem \\ a Mora com cônjuge ou \\ companheiro(a) \\ 口Mora com cônjuge ou \\ companheiro(a) e os filhos \\ 口Mora sozinho \\ 口Mora com os filhos \\ \$Mora com amigos
}

Gráfico 1.

Moradia dos psicólogos.

\section{Formação acadêmica e profissional}

De acordo com $88,6 \%$ dos participantes desta pesquisa, a escolha pelo curso de psicologia foi feita livremente, enquanto $11,4 \%$ foram influenciados por pessoas significativas no meio acadêmico e intelectual. Entre os fatores que influenciaram o curso de graduação, destacam-se os interesses, as habilidades e a vocação pessoal, apontados por toda a amostra. O estudo de Gondim et al. (2010) corrobora essa perspectiva ao afirmar que os psicólogos sentem que a escolha pelo curso de psicologia se deu livremente, e acrescentam que os fatores internos possuem maior relevância no processo da escolha profissional. Esses dados sugerem que o psicólogo brasileiro, ao optarem pelo curso de psicologia, têm a percepção de que compartilham competências, habilidades e interesses com a área escolhida. Uma escolha profissional guiada por fatores internos poderia indicar maior satisfação e comprometimento em comparação ao trabalhador que opta por uma profissão baseando-se apenas nos fatores externos, como bem apontado por Bastos et al. (2010).

De acordo com o Gráfico 2, 82,9\% dos participantes concluíram a formação acadêmica em psicologia em instituições privadas. Esse dado aparece em conformidade com a média nacional, na qual $80 \%$ dos concluintes em psicologia nos últimos anos se formaram na rede de ensino privada (Bastos et al., 2010). Em concordância, o estudo realizado pelo CRP-PR (2010) identificou que $70 \%$ dos psicólogos paranaenses são graduados na rede particular. Na pesquisa realizada no leste mineiro, $88 \%$ dos participantes se formaram nas instituições de ensino privadas (Santos et al., 2014).

Até 2018, não havia curso superior de psicologia em João Monlevade, de modo que o psicólogo que atua na cidade obteve sua formação em outro local. Ressalte-se que a cidade está situada entre a zona metropolitana de Belo Horizonte, capital do estado, e a zona metropolitana do Vale do Aço. Essas duas regiões possuem aproximadamente nove instituições privadas que ofertam o curso de psicologia e apenas uma instituição pública. Os resultados da presente pesquisa eram previstos, uma vez que, no país, a oferta de cursos de psicologia nas instituições privadas também é maior do que nas instituições públicas, assim como existem barreiras históricas que dificultam a inserção de estudantes em escolas de ensino superior pública, pelos percalços vivenciados ao longo da educação básica, em especial no ensino médio.

Quanto ao nível de satisfação com a sua graduação, $57,1 \%$ dos entrevistados se consideram satisfeitos, $22,9 \%$ se declararam moderadamente satisfeitos e 20\%, muito satisfeitos. Bardagi et al. (2008) investigaram o nível de satisfação com a graduação em um estudo com 79 psicólogos concluintes do curso de psicologia da Universidade Federal do Rio Grande do Sul. Os participantes apontaram satisfação com a formação recebida, sendo que, inclusive, $48 \%$ deles se sentiram preparados para atuar no mercado de trabalho. Da comparação dos resultados desses estudos infere-se que a formação atende às expectativas, 
embora alguns estudos apontem a insatisfação com a formação acadêmica, pós-graduada e complementar ofertada pelos cursos voltados ao campo da psicologia (Bardagi et al., 2008; Lisboa \& Barbosa, 2009; Mancebo, 997; Rezende, 2014). Evidentemente, existe uma discordância entre alguns autores quanto à satisfação com a graduação: um possível fator que explique essa diferença se atrela às expectativas presentes na escolha profissional, se elas foram totalmente realizadas. A maioria das vezes, a entrada no ensino superior é realizada com expectativas equivocadas, algumas até fantasiosas, que podem gerar decepções com a vivência acadêmica, consequentemente com a formação como um todo, por ela não atingir o esperado.

Em relação à formação continuada (Gráfico 2), $74,3 \%$ dos psicólogos têm pós-graduação em andamento ou concluída na modalidade lato sensu (especialização de 360 horas ou mais). Apenas 11,5\% da amostra possui pós-graduação stricto sensu (mestrado e doutorado). Yamamoto et al. (2010) afirmam que $52,6 \%$ da amostra da pesquisa nacional tem uma especialização, enquanto apenas $19,4 \%$ dos participantes são mestres e mestrandos, e $5 \%$, doutores e doutorandos. Acrescente-se que a pesquisa realizada pelo CRP-PR (2010) constatou que $74 \%$ dos psicólogos paranaenses concluíram especializações, 15,3\% são mestres e 3,5\%, doutores. Na pesquisa valadarense, $27,1 \%$ dos participantes tinham especialização, $11,8 \%$ eram mestres e nenhum dos participantes possuía título de doutor (Santos et al., 2014). A comparação dos dados entre as pesquisas revela disparidades, enquanto a pesquisa de opinião pública apresentou dados similares, sendo a especialização a formação continuada preferida dos psicólogos, seguida pelo mestrado e pelo doutorado (Conselho Federal de Psicologia, 2004). É possível inferir que as especializações, em diversas subáreas, são as mais frequentadas pelos psicólogos brasileiros. Os motivos associados à alta participação nas especializações não foram analisados nesta pesquisa. Seria oportuno investigar se a duração, a ênfase profissional ou acadêmica, as expectativas profissionais, os locais de oferta, a disponibilidade de tempo e o custo-benefício influenciam a escolha pelas especializações lato sensu.

Quanto à formação complementar nos últimos dois anos, de que trata o Gráfico 2, os cursos de curta duração (menos de 180 horas) são mais frequentados pelos profissionais de psicologia do munícipio de João Monlevade $(77,1 \%)$. Em segundo lugar, foram apontadas as participações nos congressos (simpósios, encontros profissionais etc.) (68,6\%). $\mathrm{O}$ inverso é observado na investigação de âmbito nacional, em que os congressos são mais frequentados $(89,7 \%)$ pelos psicólogos brasileiros. Em seguida, aparecem os cursos de curta duração $(81,9 \%)$ (Yamamoto et al., 2010). Importante ressaltar que, na presente pesquisa, $5,7 \%$ dos participantes não realizaram nenhuma atividade de formação complementar.

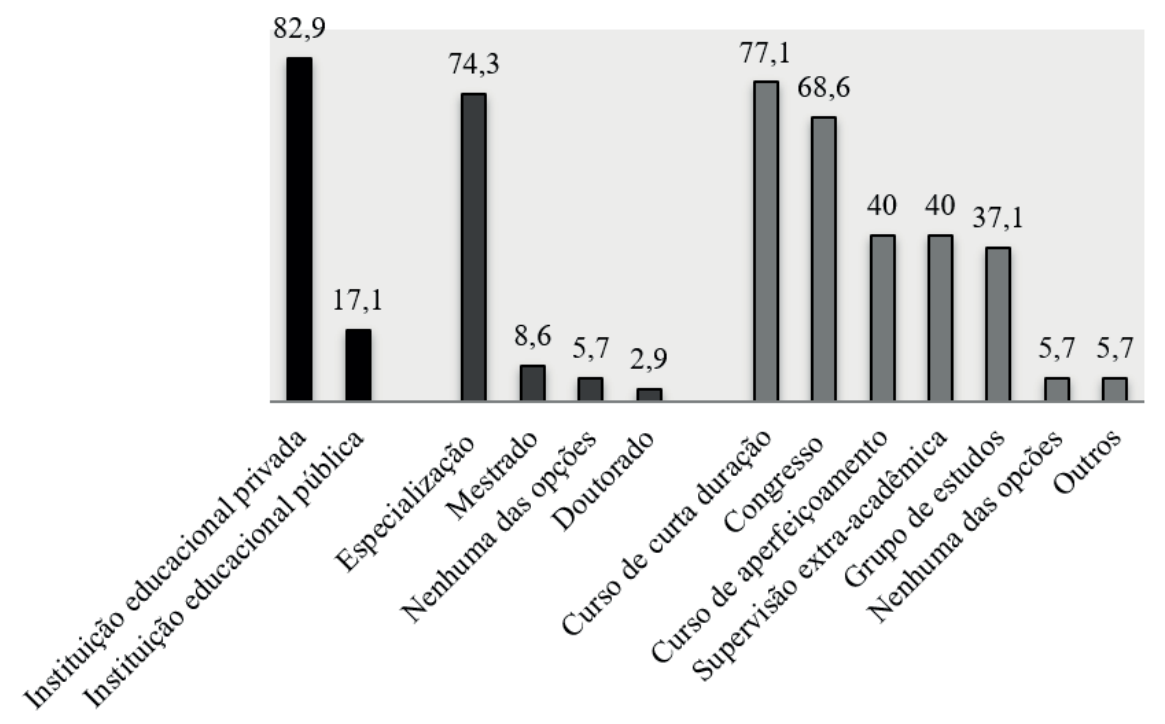

Gráfico 2.

Formação acadêmica, continuada e complementar. 
Os dados revelam investimentos em atividades de aperfeiçoamento e desenvolvimento profissional complementares à formação dos psicólogos. O envolvimento dos participantes em diferentes atividades de estudo sugere que os profissionais se preocupam com a atualização de conhecimentos, auxiliando-os a se manter em um mercado de trabalho instável. No entanto, indicadores apontam uma parcela de profissionais que não participa de nenhuma atividade voltada ao desenvolvimento profissional. Ademais, outro dado preocupante refere-se à grande quantidade de profissionais que não procuram participar de supervisão extra-acadêmica.

\section{Áreas de atuação}

Da amostra geral, 33 psicólogos são atuantes em João Monlevade e o restante não exerce atividades em psicologia no momento. Na cidade, cerca de 21.476 de seus moradores estavam empregados em 2017, o que representava $27 \%$ da população (Instituto Brasileiro e Geografia e Estatística, 2017). Grande parte dos habitantes não estava trabalhando, mas só uma quantidade mínima dos psicólogos desta pesquisa encontrava-se sem um emprego. Infere-se que a ausência de cursos de graduação na cidade implique uma quantidade moderada de profissionais atuando na região. Além disso, o fato de ser considerada uma cidade-polo regional pode ocasionar uma maior demanda de atividades profissionais.
De acordo com o Gráfico 3, 68,8\% dos psicólogos trabalham na área clínica, enquanto $43,8 \%$, na área da psicologia organizacional e do trabalho. A partir da solicitação da descrição das atividades profissionais que compõem o item outros, foram identificadas as áreas de psicologia do trânsito, saúde, organização de grupos de estudo, hospitalar, jurídica e social. O trabalho autônomo e de consultoria é visto como porta de entrada no mercado. Percebe-se que a possibilidade de trabalhar em consultórios solo, em parceria ou em equipes multidisciplinares facilita uma inserção rápida. Infere-se ainda que a oferta de cursos de aprimoramento profissional em psicologia contribui para a consolidação desse cenário ao manter o foco na área clínica. A importância do setor industrial para a região é um aspecto que pode justificar a grande porcentagem de profissionais atuando na área organizacional. Essa relevância se apresenta desde 1818, 146 anos antes da emancipação da cidade, com a construção da Forja Catalã pelo engenheiro de minas Jean-Antoine Félix Dissandes de Monlevade. Depois, em 1939, foi criada em João Monlevade a Companhia Siderúrgica Belgo-Mineira, atual ArcelorMittal Aços Longos, principal fonte de renda do município. A indústria tem um grande valor para o desenvolvimento urbano da cidade desde o seu surgimento, pois desencadeou melhorias na infraestrutura local, propiciou o crescimento da população e o aumento em atividades de produção.

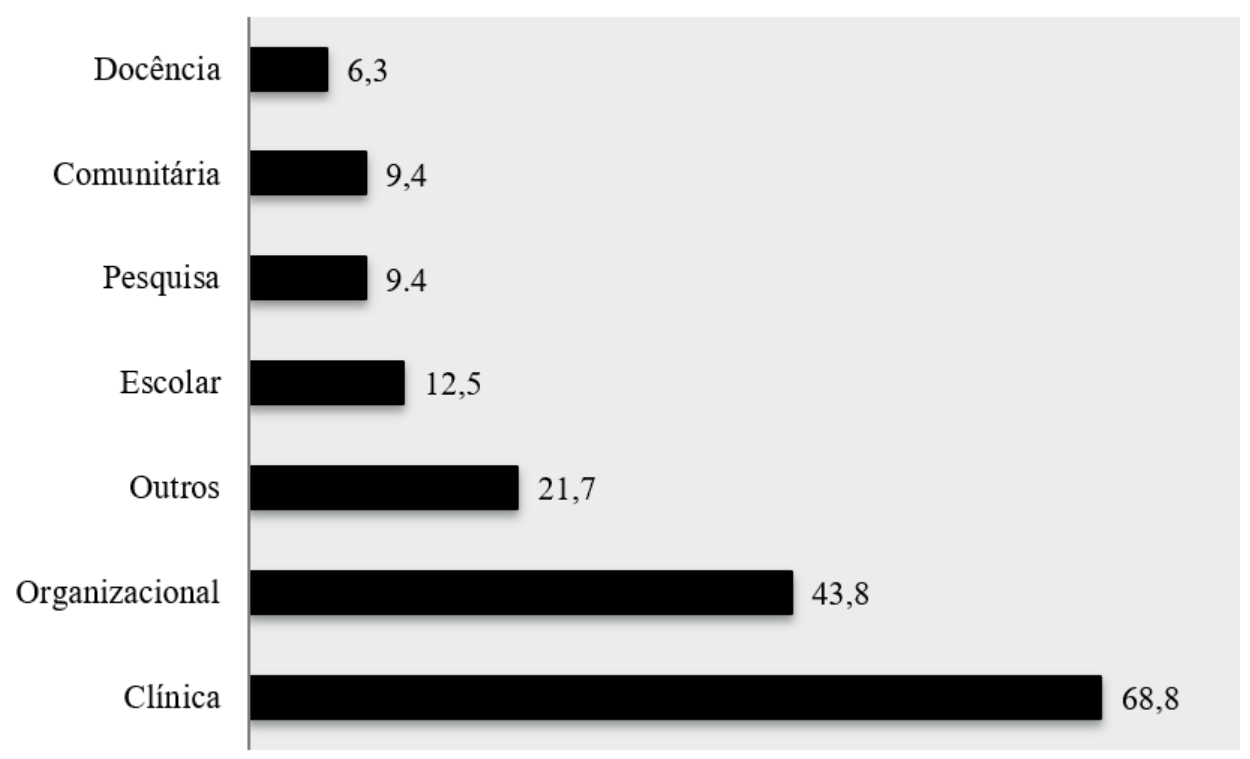

Gráfico 3.

Áreas de atuação. 
A clínica é apontada como área de atividade mais frequente entre participantes de outros estudos (Bardagi et al., 2008; Gondim et al., 2010; Conselho Regional de Psicologia do Paraná, 2010; Rezende, 2014; Santos et al., 2014). A atuação na área organizacional e do trabalho é assinalada como a segunda maior nas pesquisas de Gondim et al. (2010) e Santos et al. (2014). Já o CRP-PR (2010) aponta a área escolar em segundo lugar, e a área organizacional e do trabalho em terceiro, com a diferença de $0,3 \%$ entre elas.

Os profissionais de João Monlevade exercem desde atuação exclusiva em uma especialidade $(44,48 \%)$ até a combinada entre duas $(36,36 \%)$, três ou mais áreas $(15,15 \%)$ em suas práticas. Gondim et al. (2010) e Bardagi et al. (2008) corroboram os dados ao apresentar tanto a atuação exclusiva quanto a combinada entre duas áreas ou mais. Sobre as combinadas, os autores apontam a fácil transição de uma área para outra no exercício da psicologia.

Neste estudo, o trabalho do profissional nas áreas citadas geralmente é realizado individualmente (48,5\%). Um número relativamente similar $(42,4 \%)$ atua em equipes multi e/ ou interdisciplinares. Apenas 9,1\% dos profissionais atuam em equipes de psicólogos na cidade de João Monlevade. Em concordância, o CRP-PR (2010) apresenta que a maioria de seus profissionais opera em equipes multiprofissionais, havendo destaque entre os que trabalham no setor público, aspecto não analisado na presente pesquisa.
Entretanto, supõe-se que a atuação em grupos e equipes de trabalho esteja ligada à área e à natureza das atividades profissionais dos participantes. Embora a porcentagem de profissionais que atuam individualmente seja próxima daquela dos que trabalham em equipes, considera-se importante a articulação com outros profissionais, o que favorece o diálogo entre as diferentes áreas.

No Gráfico 4, verifica-se que entre os dezesseis respondentes, a abordagem mais utilizada é a psicanálise $(37,5 \%)$. Em seguida, encontramos as abordagens de base comportamental e cognitivista, ambas apresentando a mesma proporção (25\%). Nenhum dos respondentes sinalizou abordagens de base analítica ou psicodramática. Os dados indicam que 18,75\% desses profissionais fundamentam seu trabalho ou se identificam com mais de uma abordagem no exercício profissional. As apontadas por Gondim et al. (2010) são, em ordem de maior uso, as de base psicanalítica, humanista e comportamental. Nas últimas posições aparecem as abordagens analítica e psicodramática, dados semelhantes aos desta pesquisa. A psicanálise aparece também como a abordagem mais citada nas pesquisas de Bardagi et al. (2008) e do CRP-PR (2010). Quanto ao número de dezenove não respostas a essa questão, é possível aventar que os psicólogos não utilizam uma abordagem específica em suas atividades profissionais ou não possuem uma escolha formada em relação à linha teórica.

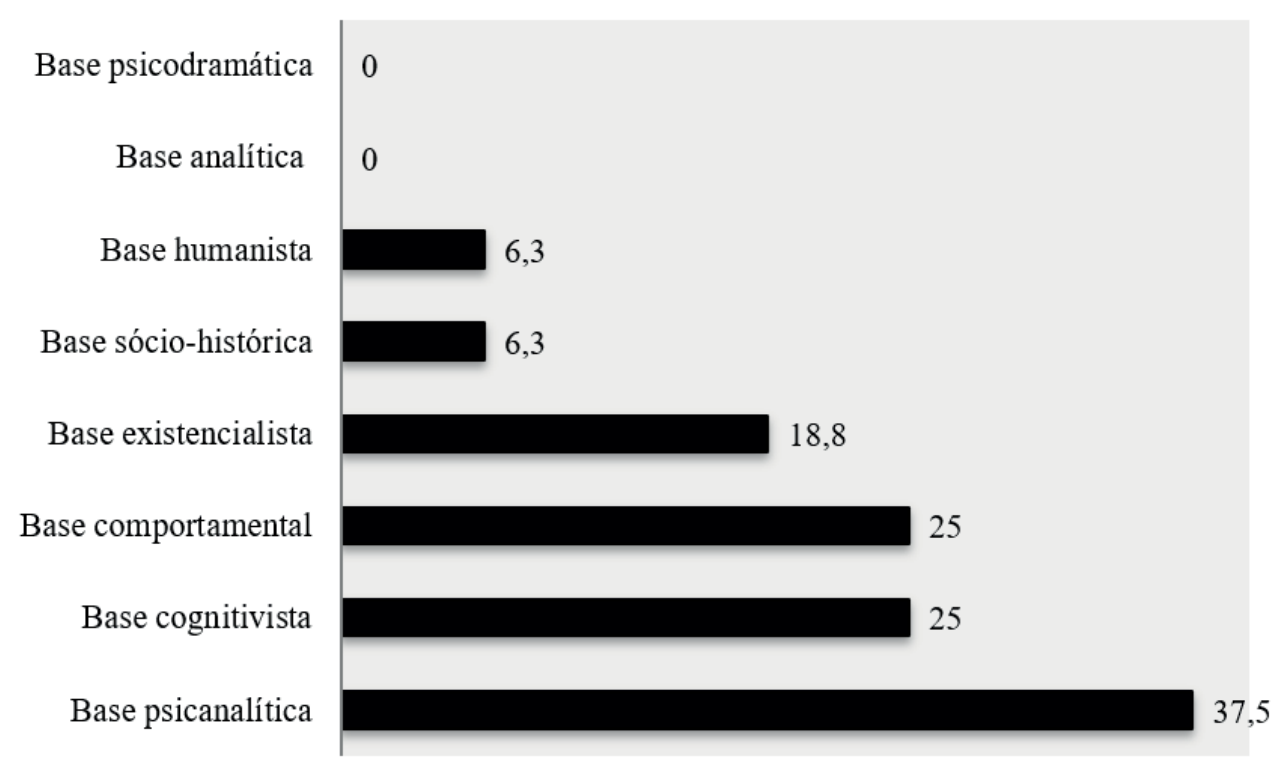

Gráfico 4.

Abordagens teórico-metodológicas. 


\section{Inserção profissional}

Durante a coleta de dados, foi constatada a presença de profissionais inscritos em João Monlevade que atuam em outras cidades e estados. Igualmente, percebe-se a participação de psicólogos residentes de cidades vizinhas no mercado de trabalho da cidade, o que pode ser decorrente da proximidade entre as localidades e de conquista do emprego via concursos públicos.

Dentre os participantes, verifica-se que $77,1 \%$ deles exercem atividades exclusivamente no campo da psicologia e $17,1 \%$ estão inseridos na psicologia e em outro campo. A baixa remuneração, a falta de oferta e as razões pessoais são os motivos associados à não inserção exclusiva na psicologia. Heloani et al. (2010) corroboram esses dados ao apresentar que mais da metade dos psicólogos inseridos no mercado de trabalho atua exclusivamente no campo da psicologia. Sobre os que exercem duas atividades profissionais, os autores inferem que os motivos sejam a remuneração e as condições do mercado. Na pesquisa do CRP-PR (2010), a melhor remuneração em outras áreas e a falta de oportunidades e o desemprego na área de psicologia foram apontados como motivos do não exercício desta profissão.

Uma pequena quantidade $(5,8 \%)$ exerce atividades profissionais apenas fora do campo da psicologia ou não exerce nenhuma atividade profissional em psicologia no momento, já tendo feito no passado. Os motivos apontados por esses dois perfis se referem à baixa remuneração e à falta de oferta de trabalho. No entanto, o desejo pela futura inserção na área prevalece, preferencialmente no setor organizacional.

Em Heloani et al. (2010), cerca de 5\% dos profissionais encontravam-se desempregados e $1,4 \%$ nunca haviam atuado como psicólogos, embora fossem habilitados na área. Os que nunca atuaram destacaram a ausência da oferta de emprego e a baixa remuneração, e manifestaram o desejo de atuar na área, bem como evidenciado em nossa pesquisa. O CRP-PR (2010) apresentou $6,69 \%$ de profissionais desempregados, porcentagem semelhante à das pesquisas supracitadas.

Entre os psicólogos empregados, 39,4\% deles se encontram em seu primeiro emprego na psicologia. Como exposto no Gráfico 5, a maioria $(63,6 \%)$ cumpre atividades profissionais de maneira autônoma e de consultoria. A segunda (54,5\%) área de maior inserção são empresas e organizações de trabalho privadas. A terceira (27,3\%), organizações sem fins lucrativos. Quanto à natureza de suas atividades profissionais, nota-se a presença de jornadas múltiplas, das quais a combinação mais comum entre as áreas de inserção é o trabalho autônomo e empresas. Segundo o CRP-PR (2010), 74\% dos psicólogos atuam no setor privado e $40,6 \%$ no setor público, enquanto $15,7 \%$ se inserem concomitantemente nos dois setores. De acordo com Macêdo et al. (2010), a maioria dos profissionais do setor privado presta serviços autônomos e de consultoria. As empresas privadas e as organizações sem fins lucrativos captam 59,7\% dos psicólogos, e o setor público emprega $40,3 \%$ no mercado de trabalho. É corriqueiro o desempenho de atividades profissionais em mais de uma área de atuação, havendo psicólogos que apresentam jornadas duplas ou triplas. Ressalte-se que esse fato pode causar uma sobrecarga ocupacional que venha a comprometer a saúde física e psicológica do profissional. A baixa remuneração da profissão pode ser correlacionada com esses dados e supõe-se que os profissionais busquem atuar em diferentes contextos como forma de complementar sua renda.

A condição socioeconômica se refere à renda e à carga horária oriundas de atividades exclusivas do campo da psicologia. Conforme apresentado no Gráfico 6, 51,5\% dos psicólogos recebe de 1 a 3 salários mínimos e 9,1\% recebe até 1 salário mínimo. Não houve menção às rendas de 9 a 12 ou de 12 a 15 salários mínimos. Em 2010, o rendimento nominal mensal per capita de $35,2 \%$ dos monlevadenses era de até metade do salário mínimo, enquanto que em 2017 a renda média apresentada por trabalhadores formais era de 2,3 salários mínimos (Instituto Brasileiro de Geografia e Estatística, 2017). Esses dados sobre a cidade estão de acordo com a pesquisa, pois demonstram que a renda da população geral é condizente com a renda média dos profissionais de psicologia que ali atuam. Dos participantes, 33,3\% possui carga horária de 31 horas a 40 horas, e 12,1\% cumpre carga horária semanal de 11 horas a 20 horas semanais.

Em nível nacional, Heloani et al. (2010) mostram que $13,2 \%$ recebem de 1 a 3 salários mínimos, 27,3\% recebe de 3 a 6 salários mínimos e 18,7\% recebem entre 6 e 8 salários mínimos. O CRP-PR (2010) apresenta que a remuneração da maioria dos profissionais no período de julho de 2009 a maio de 2010 girava em torno de 2 a 4 salários mínimos. Santos et al. (2014) apresenta a prevalência (53\%) de carga horária acima de 30 horas e menciona a importância do movimento da classe sobre a redução da jornada de trabalho para 30 horas semanais. 


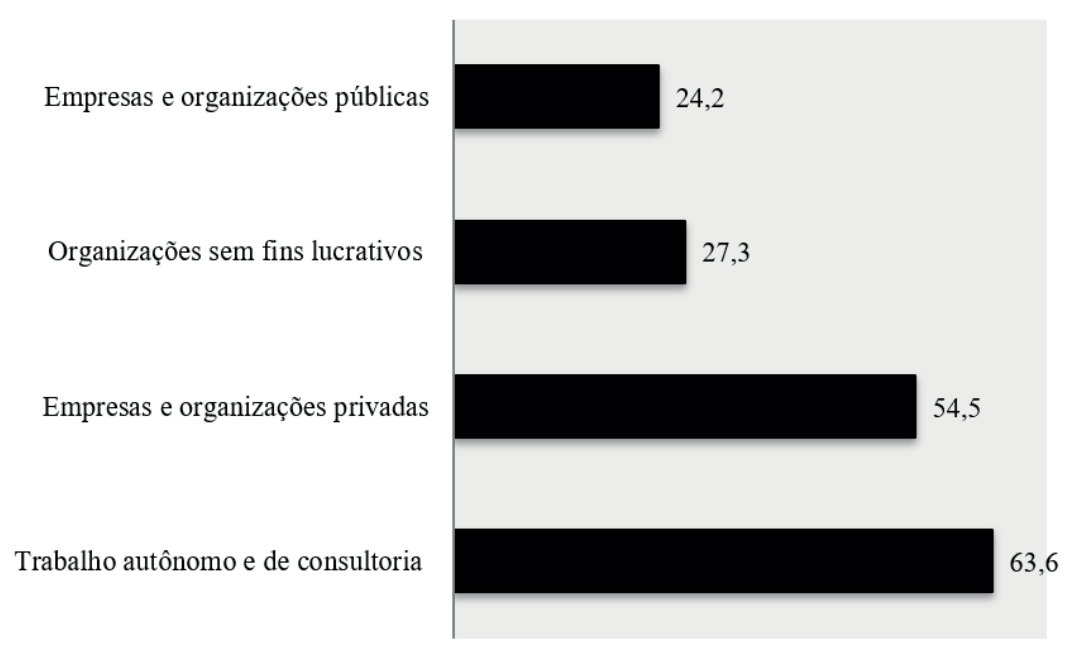

Gráfico 5.

Natureza das atividades profissionais.

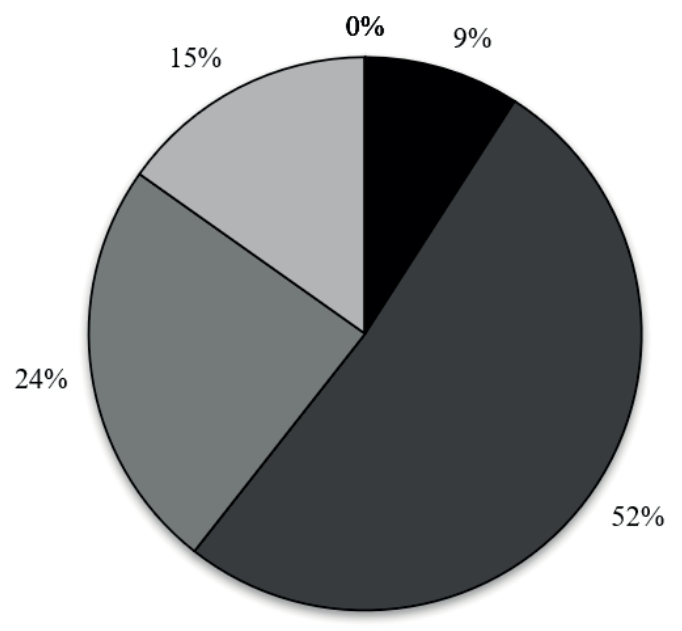

중 Nenhuma renda

- Até 1 salário mínimo

$\square$ De 1 a 3 salários mínimos

$\square$ De 3 a 6 salários mínimos

$\square$ De 6 a 9 salários mínimos

$\square$ De 9 a 12 salários mínimos

$\mathbf{Q D e} 12$ a 15 salários mínimos

Gráfico 6.

Renda mensal dos psicólogos.

Infere-se que vários aspectos da inserção do profissional no mercado de trabalho podem ser correlacionados a outros dados referentes à remuneração e à carga horária dos psicólogos, como a atuação não exclusiva em psicologia, a atuação combinada em mais de uma área, a presença de jornadas múltiplas e a forma como o profissional visualiza o mercado de trabalho em sua cidade.

Em uma questão sobre este último aspecto em João Monlevade, os participantes deveriam assinalar afirmativas com as quais concordassem. Assim, 57,14\% não marcou nenhuma das alternativas, $20 \%$ indicou acreditar que a população aceita a psicologia, e $17,14 \%$ afirmou que a profissão possui credibilidade.
Apenas 5,71\% entende que o profissional de psicologia possui espaço no mercado de trabalho em João Monlevade. Ninguém assinalou que a profissão de psicólogo é bem remunerada na cidade. Segundo Malvezzi et al. (2010), os psicólogos relatam a má remuneração da profissão e encontram dificuldades na dinâmica do mercado. Em concordância, Puente-Palacios et al. (2010) constataram uma profissão mal remunerada e uma percepção favorável no que diz respeito à credibilidade do psicólogo. De acordo com os dados, é possível constatar que o mercado é frágil, os psicólogos não se veem valorizados e o contexto atual apresenta um desafio para a prática profissional, o que demanda inovação e estratégia por parte dos profissionais. 


\section{Considerações finais}

Esta pesquisa descritivo-quantitativa foi realizada por meio de um questionário autopreenchido on-line e buscou realizar um levantamento do perfil do psicólogo residente e atuante em João Monlevade (MG), fundamentando-se na revisão de literatura sobre o perfil do psicólogo brasileiro, suas características, aspectos formativos, áreas de atuação e inserção no mercado de trabalho.

Os resultados revelam a predominância do sexo feminino e de adultos jovens na profissão, bem como de profissionais que residem com a família de origem. Apontam a forte presença de egressos da rede de ensino superior privada e sugerem que a escolha pelo curso de psicologia ocorreu por fatores subjetivos. Destacam-se o alto índice de satisfação com a formação básica e os investimentos com a formação continuada e complementar.

Foi possível verificar o alto número de profissionais que atuam exclusivamente no campo da psicologia e a tendência às áreas clínica e organizacional e à abordagem psicanalítica. Há uma porcentagem elevada que exerce trabalho autônomo e de consultoria, sendo comum jornadas múltiplas. A maioria dos profissionais recebe de 1 a 3 salários mínimos e possui carga horária semanal superior a 30 horas. O presente estudo apresenta maior porcentagem de psicólogos que recebem salários inferiores comparados aos de outras pesquisas e corrobora as mesmas em outras questões. Por fim, os profissionais consideram que o psicólogo possui pouco espaço no mercado de trabalho da cidade.

O mercado de trabalho em João Monlevade para os psicólogos não é amplo, e os indicadores apontam fragilidades, tais como: não atuação em psicologia, atuação não exclusiva, jornadas múltiplas e excessivas. Ainda que haja motivações pessoais que justifiquem esses dados, não há como negar a influência do fator financeiro. Cabe a reflexão sobre o papel do órgão representante da psicologia na divulgação de suas práticas profissionais e sobre leis e políticas relacionadas à profissão de psicólogo em um âmbito nacional. Não menos importante, deve haver um movimento dos próprios psicólogos no sentido de conscientizar a população sobre o papel deles na vida cotidiana, para que a desinformação sobre a classe seja desconstruída e um novo saber, apreendido.

Uma das limitações deste trabalho foi utilizar, predominantemente, o livro O trabalho do psicólogo no Brasil, incorporando de forma sucinta outras publicações na revisão de literatura. Outras limitações se referem a tópicos não abordados e questões que obtiveram não respostas. Acrescente-se o alcance limitado do público-alvo. Houve dificuldade em localizar e contatar todos os psicólogos inscritos na lista disponibilizada pelo conselho em seu site. Entre os profissionais aos quais as pesquisadoras tiveram acesso e que se enquadravam nos critérios da pesquisa, muitos deixaram de participar por motivos desconhecidos.

Dessa forma, sugere-se aos futuros pesquisadores que contemplem outras fontes na revisão de literatura para que haja uma ampliação de dados comparativos, antigos e novos. Indica-se incluir nas próximas investigações os aspectos mencionados que não foram observados nesta pesquisa, visto que essas informações são importantes para delinear o perfil do psicólogo monlevadense. Acerca das questões que apresentaram não respostas, recomenda-se um planejamento consistente da estrutura do questionário para que sejam evitadas suposições sobre o motivo de os respondentes deixarem questões em branco. Para se obter um melhor alcance do público-alvo, sugere-se um maior investimento na divulgação da pesquisa, ou até mesmo a utilização de uma amostragem diferente da utilizada nesta metodologia, para que os resultados sejam os mais fiéis possíveis.

Entre os fatores que ocasionam a presença de poucos profissionais atuando no mercado de trabalho em João Monlevade, infere-se que isso decorra de dificuldades de inserção em vagas formais dentro de empresas, clínicas e instituições sociais; da ausência de credibilidade profissional, o que reduz sua empregabilidade; da instabilidade econômica do país, que reduz investimentos na área de saúde mental; da ausência de reconhecimento da população, que impossibilita a permanência nos postos de atuação profissional. Atrelada a esses fatores, a atuação do psicólogo ainda se faz dentro dos padrões tradicionais, com predomínio das áreas de psicologia clínica, psicanalítica e organizacional, permanecendo pouco valorizada social e financeiramente, o que reduz seu status social no desenvolvimento do bem-estar psicossocial dos moradores da região. Uma questão que surge nesse cenário é a percepção que os próprios psicólogos têm sobre empregabilidade e empreendedorismo, assim como a representação social que existe diante da atuação da psicologia. 


\section{Referências}

Amendola, M. F. (2014). Formação em psicologia, demandas sociais contemporâneas e ética: Uma perspectiva. Psicologia: Ciência e Profissão, 34(4), 971-983. https://dx.doi.org/10.1590/1982-370001762013

Bardagi, M. P., Bizarro, L., Andrade, A. M. J., Audibert, A., \& Lassance, M. C. P. (2008). Avaliação da formação e trajetória profissionalnaperspectivadeegressosdeum cursodepsicologia.Psicologia:CiênciaeProfissão, 28(2),304-315, 2008. http://pepsic.bvsalud.org/scielo.php?script=sci_arttext\&pid=S1414-98932008000200007\&lng=pt\&tlng=pt

Bastos, A. V. B., \& Gondim, S. M. G. (Orgs.) (2010). O trabalho do psicólogo no Brasil. Porto Alegre, RS: Artmed.

Bastos, A. V. B., Gondim, S. M. G., \& Borges-Andrade, J. E. (2010). As mudanças no exercício profissional da psicologia no Brasil: $\mathrm{O}$ que se alterou nas duas últimas décadas e o que vislumbramos a partir de agora? In Bastos, A. V. B, \& Gondim, S. M. G. (Orgs.), O trabalho do psicólogo no Brasil (pp. 419-444). Porto Alegre, RS: Artmed.

Bastos, A.V. B., Gondim, S. M. G., \& Rodrigues, A. C. (2010). Uma categoria profissional em expansão quantos somos e onde estamos? In Bastos, A. V. B., \& Gondim, S. M. G. (Orgs.), O trabalho do psicólogo no Brasil (pp. 32-44). Porto Alegre, RS: Artmed.

Brasil. (1962). Parecer no 403, de 19 de dezembro de 1962. Fixa o currículo mínimo e a duração do curso de psicologia. Brasília, DF: Conselho Federal de Educação. http://abepsi.org.br/wp-content/uploads/2011/07/ 1962-parecern403de19621.pdf

Brasil. (2011). Resolução no 5, de 15 de março de 2011. Institui as diretrizes curriculares para os cursos de graduação em psicologia, estabelecendo normas para o projeto pedagógico complementar para a formação de professores em psicologia. Brasília, DF: Conselho Nacional de Educação. http://portal.mec.gov.br/index.php?option=com_ docman\&view=download\&alias=7692-rces005-11-pdf\&category_slug=marco-2011-pdf\&Itemid=30192

Brasil. (2012). Resolução no 466, de 12 de dezembro de 2012. Aprova normas regulamentadoras de pesquisas envolvendo seres humanos. Brasília, DF: Diário Oficial da União. http://conselho.saude.gov.br/resolucoes/2012/Reso466.pdf

Conselho Federal de Psicologia. (2004). Pesquisa de Opinião IBOPE - Psicólogo brasileiro. Brasília, DF: Autor. http://site.cfp.org.br/publicacao/pesquisa-de-opinio-ibope-psiclogo-brasileiro/

Conselho Federal de Psicologia. (2018). A psicologia brasileira apresentada em números. Infográfico. Brasília, DF. http://www2.cfp.org.br/infografico/quantos-somos/

Conselho Regional de Psicologia do Paraná. (2010). Levantamento do perfil profissional e das condições de trabalho dos psicólogos do Paraná: CRP-08. Relatório final de pesquisa. Curitiba, PR: CRP-PR. http://www.old.crppr.org. $\mathrm{br} /$ download/265.pdf

Gerhardt, T. E., Ramos, I. C. A., Riquinho, D. L., \& Santos, D. L. (2009). Estrutura do projeto de pesquisa. In T. E. Gerhardt \& D. T. Silveira, D. T. (Orgs.), Métodos de pesquisa (pp. 65-88). Porto Alegre, RS: Editora da UFRGS.

Gil, A. C. (2008). Métodos e técnicas de pesquisa social (6a ed.). São Paulo, SP: Atlas.

Gondim, S. M. G., Bastos, A. V. B., \& Peixoto, L. S. A. (2010). Áreas de atuação, atividades e abordagens teóricas do psicólogo brasileiro. In A. V. B. Bastos \& S. M. G. Gondim, S. M. G. (Orgs.), O trabalho do psicólogo no Brasil (pp. 174-199). Porto Alegre, RS: Artmed.

Gondim, S. M. G., Magalhães, M. O., \& Bastos, A. V. B. (2010). Escolha da profissão: As explicações construídas pelos psicólogos brasileiros. In A. V. B. Bastos \& S. M. G. Gondim (Orgs.), O trabalho do psicólogo no Brasil (pp. 66-84). Porto Alegre, RS: Artmed.

Heloani, R., Macêdo, K. B., \& Cassiolato, R. (2010). O exercício da profissão: Características gerais da inserção profissional do psicólogo. In A. V. B. Bastos \& S. M. G. Gondim (Orgs.), O trabalho do psicólogo no Brasil (pp. 107-130). Porto Alegre, RS: Artmed.

Instituto Brasileiro de Geografia e Estatística. (2017). Estimativas da população residente com data de referência $1^{\circ}$ de julho de 2017. Rio de Janeiro, RJ: Autor. https:/ / cidades.ibge.gov.br/brasil/mg/joao-monlevade/panorama

Lisboa, F. S., \& Barbosa, A. J. G. (2009). Formação em psicologia no Brasil: Um perfil dos cursos de graduação. Psicologia: Ciência e Profissão, 29(4), 718-737. https://dx.doi.org/10.1590/S1414-98932009000400006

Lhullier, L. A., \& Roslindo, J. J. (2013). As psicólogas brasileiras: Levantando a ponta do véu. In L. A. Lhullier (Org.), Quem é a psicóloga brasileira? Mulher, psicologia e trabalho (pp. 19-51). Brasília, DF: Conselho Federal de Psicologia. https://site.cfp.org.br/publicacao/quem-e-a-psicologa-brasileira/ 
Macêdo, K. B., Heloani, R., \& Cassiolato, R. (2010). O psicólogo como trabalhador assalariado: setores de inserção, locais, atividades e condições de trabalho. In A. V. B. Bastos S. M. G. Gondim (Orgs.), O trabalho do psicólogo no Brasil (pp. 131-150). Porto Alegre, RS: Artmed.

Malvezzi, S. (2010). A profissionalização dos psicólogos: Uma história de promoção humana. In A. V. B. Bastos \& S. M. G. Gondim (Orgs.), O trabalho do psicólogo no Brasil (pp. 17-31). Porto Alegre, RS: Artmed.

Malvezzi, S., Souza, J. A. J., \& Zanelli, J. C. (2010). Inserção no mercado de trabalho: Os psicólogos recém-formados. In A. V. B. Bastos \& S. M. G. Gondim (Orgs.), O trabalho do psicólogo no Brasil (pp. 85-106). Porto Alegre, RS: Artmed.

Mancebo, D. (1997). Formação do psicólogo: uma breve análise dos modelos de intervenção. Psicologia: Ciência e Profissão, 17(1), 20-27. https://dx.doi.org/10.1590/S1414-98931997000100004

Nepomuceno, R. F., \& Witter, G. P. (2010). Influência da família na decisão profissional: opinião de adolescentes. Psicologia Escolar e Educacional, 14(1), 15-22. https:// dx.doi.org/10.1590/S1413-85572010000100002

Pacheco, D. A. (2013). O psicólogo organizacional e sua inserção no mercado de trabalho (Monografia). Universidade Federal do Rio Grande do Sul, Porto Alegre, RS. http://www.lume.ufrgs.br/handle/10183/70051

Pessotti, I. (1988). Notas para uma história da psicologia brasileira. In Conselho Federal de Psicologia (Org.), Quem é o psicólogo brasileiro? (pp. 17-31). São Paulo, SP: Edicon.

Puente-Palacios, K., Abbad, G. S., \& Martins, M. C. F. (2010). Imagem da profissão e perspectivas futuras de mudança. In A. V. B. Bastos \& S. M. G. Gondim(Orgs.), O trabalho do psicólogo no Brasil (pp. 402-418). Porto Alegre, RS: Artmed.

Rezende, L. B. (2014). Da formação à prática do profissional psicólogo: Um estudo a partir da visão dos profissionais (Dissertação de mestrado). Universidade Federal de Juiz de Fora, Juiz de Fora, MG. https://repositorio.uff.br/ jspui/bitstream/uff/553/1/leonicebarbaraderezende.pdf

Santos, K. R., Monteiro, L. G., Torres, M. L. C., Sousa, L. G., \& Coelho, A. R. (2014). Perfil dos psicólogos inscritos na subsedelestedo CRP-04.Psicologia:CiênciaeProfissão, 34(4),864-878.https://dx.doi.org/10.1590/1982-370000162013

Serviço Brasileiro de Apoio às Micro e Pequenas Empresas. (2014). Identidade dos municípios mineiros: João Monlevade. Belo Horizonte, MG. https://www.sebraemg.com.br/atendimento/bibliotecadigital/documento/ Diagnostico/Identidade-dos-Municipios-Mineiros---Joao-Monlevade

Silveira, D. T., \& Córdova, F. P. (2009). A pesquisa científica. In T. E. Gerhardt \& D. T. Silveira (Orgs.), Métodos de pesquisa (pp. 31-42). Porto Alegre, RS: Editora da UFRGS.

Souza, R. L., \& Correia, L. V. (2007). Perfil do psicólogo na região do Vale do Aço. Principium Online: Iniciação Científica no Unileste-MG, 1(2), 141-154.

Yamamoto, O. H., Souza, J. A. J., Silva, N., \& Zanelli, J. C. (2010). A formação básica, pós-graduada e complementar do psicólogo no Brasil. In A. V. B. Bastos \& S. M. G. Gondim (Orgs.), O trabalho do psicólogo no Brasil (pp. 45-65). Porto Alegre, RS: Artmed.

\section{Aline Benício Muniz}

Bacharel em Psicologia pelo Centro Universitário do Leste de Minas Gerais (Unileste), Coronel Fabriciano - MG. Brasil. E-mail: psialinemuniz@gmail.com

(1) https://orcid.org/0000-0001-7532-5318

\section{Lorraynne Moura de Amorim}

Bacharel em Psicologia pelo Centro Universitário do Leste de Minas Gerais (Unileste), Coronel Fabriciano - MG. Brasil.

E-mail: lorraynneamorim@gmail.com

(1) https://orcid.org/0000-0003-1490-2876

\section{Shyrlleen Christieny Assunção Alves}

Psicóloga, professora adjunta do Centro Universitário do Leste de Minas Gerais. Mestre em Psicologia Social pela Universidade Federal de Minas Gerais. Doutora em Psicologia Social e do trabalho pela Universidade de São Paulo.

Coronel Fabriciano - MG. Brasil.

E-mail: shyrlleen@gmail.com

(1) https://orcid.org/0000-0002-2696-0232 
Endereço para envio de correspondência:

Núcleo de Atividades Práticas em Psicologia (NAPP) - Centro Universitário Católica do Leste de Minas Gerais (Unileste). Avenida Presidente Tancredo de Almeida Neves, 3.500, Bloco B - Campus Coronel Fabriciano,

Universitário. CEP: 35171-302. Coronel Fabriciano - MG. Brasil.

Recebido 23/08/2018

Aceito 14/10/2019

Received 23/08/2018

Approved 14/10/2019

Recibido 23/08/2018

Aceptado 14/10/2019

Como citar: Muniz, A. B., Amorim, L. M., Alves, S. C. A. (2020). Perfil do Psicólogo Residente e Atuante em João Monlevade (MG): Perfil do Psicólogo Monlevadense. Psicologia: Ciência e Profissão, 40, 1-18.

https://doi.org/10.1590/1982-3703003212944

How to cite: Muniz, A. B., Amorim, L. M., Alves, S. C. A. (2020). Profile of the Resident and Acting Psychologist in João Monlevade, Minas Gerais. Psicologia: Ciência e Profissão, 40, 1-18. https://doi.org/10.1590/1982-3703003212944

Cómo citar: Muniz, A. B., Amorim, L. M., Alves, S. C. A. (2020). Perfil del Psicólogo Residente y Actuante en João Monlevade, Minas Gerais. Psicologia: Ciência e Profissão, 40, 1-18. https://doi.org/10.1590/1982-3703003212944 